\title{
LA MOVILIZACIÓN EN TIEMPOS DE GUERRA. LOS VOLUNTARIOS ALEMANES EN CHILE DURANTE LA PRIMERA GUERRA MUNDIAL: REACCIONES Y PROBLEMAS'
}

\author{
Mobilization in times of war. German volunteers \\ in Chile during the First World War: reactions and problems
}

\author{
Juan Luis Carrellán Ruiz \\ Universidad de Córdoba, España
}

\begin{abstract}
Resumen: La historiografía chilena no ha analizado en profundidad los impactos que sobre la sociedad chilena causó la Primera Guerra Mundial. En este trabajo, pretendemos dar algunas respuestas sobre los comportamientos y los problemas a los que se enfrentaron los voluntarios alemanes residentes en Chile que pretendieron llegar al frente europeo, así como acerca de la organización de la retaguardia de la colonia alemana en este país americano.
\end{abstract}

Palabras clave: alemanes, Chile, Primera Guerra Mundial, movilización, retaguardia.

Abstract: Chilean historiography has not analyzed in depth the impacts on Chilean society caused by the First World War. In this work, we intend to give some answers about the behaviors and problems faced by the German volunteers residing in Chile who tried to reach the European front, as well as the study of the rearguard of the German colony in this American country.

Keywords: Germans, Chile, First World War, mobilization, rearguard.

\section{Introducción}

La Primera Guerra Mundial (en adelante PGM) ha sido destacada por muchos autores como uno de los acontecimientos más relevantes del pasado. La Gran Guerra, junto con la Revolución rusa, produjo una ruptura con el orden liberal que se había consolidado en el siglo XIX. Este desprestigio de las democracias

1. Este artículo es el resultado del proyecto de investigación financiado por la Universidad de La Frontera (Chile), proyecto DI15-0026, institución en la que presté mis servicios entre 2013 y 2017. 
liberales provocó la aparición de gobiernos autoritarios que intentaron frenar el desarrollo del comunismo. Hubo que esperar a la Segunda Guerra Mundial para que las democracias liberales tomaran de nuevo impulso en el mundo occidental y se presentaran como la alternativa al comunismo. Este ciclo iniciado durante la guerra de 1914-1918 se cerraría con la caída de la URSS en la década de 1990 (Hobsbawm, 2000: 22).

La PGM aceleró los procesos políticos, económicos y sociales que ya estaban en marcha, como el triunfo de la Revolución rusa. No obstante, a pesar de la relevancia de la PGM, la historiografía iberoamericana no ha prestado mucha atención a los efectos de esta en sus sociedades. Uno de los primeros historiadores en preocuparse de esta temática fue Olivier Compagnon, que achaca ese desinterés a la visión tradicional de lberoamérica como región periférica a la que afectan poco o nada los impactos geopolíticos generados desde las potencias europeas y Estados Unidos, considerados el centro del sistema internacional.

Otros motivos a los que alude Compagnon para justificar ese vacío historiográfico serían el hecho de que la guerra no se libró en los países latinoamericanos, que fueron un espacio marginal para los países combatientes; y también el escaso número de combatientes procedentes de lberoamérica respecto al total de los soldados participantes en el conflicto. Solo Brasil envió tropas al frente de combate meses antes de anunciarse el armisticio, aunque la mayoría de los países americanos rompieron relaciones con los imperios centrales y muchos firmaron el Tratado de Versalles junto con los aliados (Compagnon, 2007: 77-78).

Por lo general, la guerra de 1914 ha tenido la atención de los historiadores iberoamericanos en relación con sus efectos económicos y con la evolución de los vínculos diplomáticos de los distintos países del área con las potencias beligerantes, pero se han dejado de lado los impactos en sus sociedades. Sin embargo, habría que advertir que fueron autores argentinos, como María Inés Tato y Hernán Otero, por citar solo a dos, los que, en la primera década del siglo XXI, se dedicaron a dar respuestas a los comportamientos de la sociedad argentina durante el conflicto bélico (Tato, 2014a, 2014b; Otero, 2009).

La conmemoración del centenario del comienzo de la PGM ha producido un mayor interés por esta temática en Iberoamérica. Se han desarrollado seminarios en distintas universidades y han proliferado publicaciones en forma de artículos (Ramírez Bacca, 2015; Palamara, 2015), dossieres en revistas, ${ }^{2}$ monografías (Novak y Ortiz, 2014; Rinke, 2017) y obras colectivas (Compagnon et al., 2018), que han avanzado en el conocimiento de los efectos de esta guerra sobre cada país de la región, si bien son muy escasos los estudios de conjunto de las naciones latinoamericanas.

Para el caso de Chile, nos encontramos con la tónica general de la historiografía iberoamericana. Los investigadores se han detenido poco en esa temática y los trabajos sobre el período se basan en los impactos económicos, sobre todo en el declive del comercio del salitre y su consiguiente conflictividad social, además de en la cuestión de la sustitución de la hegemonía económica de Gran

2. Como los coordinados por Stefan Rinke (2014a) y Enrique Fernández Domingo (2018). 
Bretaña por Estados Unidos. A esto hay que sumar los estudios sobre la neutralidad y las relaciones de Chile con las potencias en conflicto (Oyarzún, 2002; Bravo Valdivieso, 2005).

Entre los trabajos más importantes figura la obra de Juan Ricardo Couyoumdjian (1986) en la que se estudian la situación política, social y económica de Chile en 1914, sus relaciones con Gran Bretaña y los vínculos económicos con Alemania y Estados Unidos. Además, se dedica un apartado al análisis de la coIonia británica residente en el país, principalmente en la ciudad de Valparaíso. En Chile, igual que en el resto de los países latinoamericanos, la conmemoración del centenario de la PGM ha promovido la aparición de publicaciones que han contribuido al conocimiento de los impactos de la PGM en este país. ${ }^{3}$

En los últimos años, han aparecido varios estudios sobre los voluntarios de origen europeo residentes en Chile que fueron a luchar en el frente europeo (Legarraga, 2006; Pérez, 2010; Carrellán y Llosa, 2018). En este trabajo, nos proponemos analizar el reclutamiento de los voluntarios alemanes residentes en Chile al comenzar la PGM y la organización de la retaguardia para entender, en una primera aproximación, los problemas a los que debieron enfrentarse cuando estalló el conflicto, así como las reacciones que tuvieron ante los mismos. Para hacer este estudio nos hemos basado en documentación de archivo varia y en noticias de prensa. ${ }^{4}$

\section{La inmigración alemana en Chile}

La historiografía chilena ha dedicado bastante atención a la inmigración europea y, en particular, ha tratado de explicar los procesos de asentamiento de estos colectivos durante el siglo XIX y la primera mitad del XX; sin embargo, se ha centrado en describir y cuantificar estas colectividades, dónde se establecían, a qué se dedicaban económicamente y qué instituciones crearon. ${ }^{5}$ En cambio, son escasos los estudios sobre sus comportamientos políticos o sus debates internos, aunque hay algunas excepciones, como los trabajos sobre los españoles en Chile durante la segunda república, la guerra civil y el franquismo en España (Almonacid, 2004; Estrada Turra, 2009).

La inmigración europea en Chile contó con el apoyo de las autoridades chilenas, que dedicaron sus esfuerzos a dirigirla al sur del país. Para los represen-

3. Véanse: Carrellán y Sáez (2014), Samaniego y Medina (2016) y Fernández Domingo (2016).

4. Los periódicos consultados han sido El Mercurio y El Diario llustrado, editados en Santiago de Chile y de tirada nacional, así como El Sur, publicado en Concepción y de ámbito regional. En los tres diarios se han analizado las noticias de los meses de agosto y septiembre de 1914. Por lo que respecta el material de archivo, los fondos consultados se encuentran en el Archivo General Histórico del Ministerio de Relaciones Exteriores de Chile, ubicado en Santiago de Chile, y el Centre des Archives Diplomatiques de Nantes, ubicado en esta ciudad francesa.

5. Alfonso (1900); Mier (1910); Soto (1917); Aranda, Llarena y Tenajo (1920); Pellegrini y Aprile (1924); Philippi (1946); Blancpain (1974); Young (1974); Waldmann (1988); Güenaga de Silva (1989); Salinas Meza (1992); Bernedo (1999); Krebs, Tapia y Schmid (2001); Anwandter (2001); Estrada Turra (2005, 2011, 2013 y 2014); Sanhueza (2006); Alarcón (2009); Winkler (2010); Brahm (2014). 
tantes del Estado, los europeos aumentarían la población en el territorio, pondrían en cultivo las tierras agrícolas y fomentarían la ampliación del ferrocarril y la expansión del comercio y la industria. Pero lo más valioso para ellos era que extenderían su moral y civilización entre los habitantes del sur de Chile, ya que pensaban que la cultura europea era superior a la que existía en aquellos territorios. El plan estatal era construir una sociedad bajo la ideología dominante en la época: la de la asimilación del estilo de vida que las autoridades estipulaban como el más válido (Gordon, 1978).

Y dentro de este plan, los habitantes autóctonos indígenas, los chilenos no indígenas y los extranjeros debían asimilar los valores de la identidad nacional chilena. Sin embargo, existía el peligro de que los europeos estuvieran dispuestos a mantener su lengua, sus costumbres y sus principios y crearan enclaves étnicos, una amenaza que los legisladores chilenos estaban dispuestos a combatir, porque «tiende a perpetuar ideas y sentimientos contrarios a nuestra unidad nacional». ${ }^{6}$

La historiografía ha confirmado que los temores de las autoridades no iban desencaminados, ya que las colonias europeas intentaron mantener viva su cultura original y buscaron convivir con otros inmigrantes de su nacionalidad, agrupándose en instituciones (compañías de bomberos, de socorros mutuos, etc.) y fundando colegios y periódicos en su lengua. Por ello, el Estado inició una labor de «chilenización» de estos individuos, que ha sido analizada por diferentes autores, como Mario Góngora (1998) y otros más recientes como Ana María Stuven (2009) o Gabriel Cid (2009), por citar algunos.

La mayoría de los autores admiten la elaboración de una política racista por parte de las autoridades estatales que privilegiaron la llegada de europeos del norte, preferiblemente alemanes. Pero parece claro que esta migración se vio frustrada por varios motivos, como su reorientación a finales del siglo XIX hacia Estados Unidos y como las trabas de los gobiernos germánicos a los destinos latinoamericanos a causa de los atropellos que padecieron muchos de sus nacionales en estas latitudes, en particular, en Brasil (Estrada Turra, 2018: 24).

Sea como fuera, la inmigración alemana en Chile tuvo su origen en el siglo XIX gracias a una política planificada por el Estado chileno que tuvo el sur de Chile como protagonista. En 1850 se inició la colonización de Valdivia y Llanquihue, seguida de la de las provincias de Malleco y Cautín, hacia 1882, momento en el que se intensifica este proceso (Blancpain, 1987), puesto que este territorio se incorpora de facto a la nación en esta década.

Según Vera de Flachs, las fuentes estadísticas alemanas estiman que entre 1871 y 1914 emigraron a Chile 9.859 alemanes, cifra muy baja si se compara con los más de 46.000 que llegaron a Brasil, el primer destino de Latinoamérica, entre 1875 y 1914. El período coincide con la aceleración del proceso industrial de Alemania y el aumento significativo de la población, producto de la dis-

6. Extraído del Anteproyecto de Ley de la Comisión de Gobierno, Relaciones Exteriores y Colonización de la Cámara de Diputados de 1886, documento incluido en Harris Bucher (2012: 405-406). 
minución de la tasa de mortalidad que experimentó el nuevo Estado germano unificado (Vera de Flachs, 1994: 67-68, 77 y 80-82).

Estrada Turra (2014) afirma que en Chile los alemanes fueron la colectividad extranjera con más asociaciones y que esta circunstancia está relacionada con su propensión al aislamiento de la sociedad de acogida. El objetivo de estas instituciones era proteger sus valores culturales y su identidad étnica, y sus esfuerzos más importantes se orientaron a la preservación de su idioma y su religión, para lo cual crearon colegios con esta finalidad.

Para el caso de Valparaíso, entre los miembros de la colonia hubo dos grupos diferenciados en función de su posición económica. Por un lado, tenemos un grupo más elitista y aislado, formado por los funcionarios de las sucursales de empresas matrices ubicadas en Alemania (casas importadoras, bancos, navieras, aseguradoras), que solían llegar a Chile por un determinado número de años. Por otro lado, había otro grupo, el mayoritario, que estaba constituido por pequeños empresarios de establecimientos comerciales y trabajadores de negocios. Los primeros fundaron, en 1838, el Club Alemán, que cobraba unas cuotas que solo se las podían permitir los individuos más privilegiados de la colonia (Estrada Turra, 2014: 140-144).

Sin embargo, no solo llegaron a Chile alemanes: también suizos, franceses, italianos, británicos y españoles, entre otros. En los censos chilenos, los extranjeros no fueron muy numerosos, si se comparan con el resto de la población. Representaban el 4,3\%, en 1907, y el 3\%, en 1920, según los censos oficiales. $Y$ eran menos numerosos aún, si equiparamos estas cifras con las registradas en otros países vecinos, como Argentina, Uruguay o Brasil.

En el caso de los alemanes, en el censo chileno de 1907 había 10.724 personas de esa nacionalidad. Justo después de la PGM, el censo de 1920 señalaba la existencia de 8.950 alemanes. Entre los dos censos hay una disminución de más de 1.700 individuos. Las hipótesis son varias: una es que parte de este contingente se marchó a Europa a luchar al frente de batalla y no regresó, bien porque muriera allí o porque decidiera quedarse en el Viejo Mundo. Otra es que numerosos individuos alemanes obtuvieran la nacionalización chilena, entre otras causas para evitar el control de las autoridades diplomáticas alemanas en Chile durante la guerra. Finalmente, la última hipótesis, la que consideramos menos plausible, es que hubiera un alto número de fallecidos alemanes en territorio chileno.

Blancpain afirma que el Gobierno chileno procuró mantener el equilibrio en sus relaciones con las potencias europeas. Hasta 1870, los Estados alemanes solo ofrecían a sus emigrantes, pero a partir de esa fecha «el Reich actúa como feliz contrapeso a la dominación económica británica y, luego, a las ambiciones panamericanas de Estados Unidos» (Blancpain, 1987: 147).

En este sentido, la guerra del Pacífico (1879-1883) supuso el origen de una rivalidad y una desconfianza entre Chile y Estados Unidos que llegaría hasta la PGM. El desencuentro se inició cuando Estados Unidos se dispuso a mediar en esta contienda entre Chile, por un lado, y Perú y Bolivia, por otro, y ejercer su hegemonía en el continente, pero Chile se mostró reacio a este arbitraje y decidió quedarse con territorios peruanos y bolivianos, sabiendo que los estadounidenses carecían de la fuerza militar para impedirlo. Luego vendría el apoyo norteame- 
ricano a Balmaceda, el incidente del navío Baltimore, por el que los dos países estuvieron a punto de entrar en una guerra, y el caso de la empresa Alsop, en 1909, en el que Estados Unidos amenazó con romper relaciones si no se atendía a las peticiones de la empresa (Meneses, 1989: 32-33, 56-57, 93, 130-133 y 136).

Precisamente fue durante la guerra del Pacífico cuando la diplomacia alemana logró parar una intervención de tropas europeas (británicas y francesas, en su mayoría) en el conflicto (Barros, 1970: 364). Desde entonces, para Blancpain la amistad germano-chilena se hizo más patente y favoreció el intercambio comercial bilateral. En 1890 Alemania era el segundo comprador y vendedor de Chile, y en 1900 la agricultura alemana era la primera consumidora europea de nitratos de Chile (Blancpain, 1987: 148-149). El traslado a Hamburgo de ese salitre se hacía principalmente a través de la compañía alemana Kosmos, fundada en 1872 para participar en el tráfico comercial entre Alemania y América del Sur, con atraques en Buenos Aires, Valparaíso, Arica y El Callao.

\section{Los alemanes en Latinoamérica en 1914}

El 28 de junio de 1914 se produjo el asesinato del heredero del Imperio austrohúngaro en Sarajevo, que desencadenó el enfrentamiento de las principales potencias europeas. Estas se hallaban agrupadas en dos bloques: inicialmente, Alemania y el Imperio austrohúngaro, por un lado, y Francia, Gran Bretaña y Rusia, por otro. Mientras, en América Latina, las comunidades de inmigrantes alemanes y sus descendientes quedaron sin comunicaciones directas con Alemania. Rinke (2014) ha analizado las repercusiones de la guerra en las comunidades residentes en Argentina, Brasil y Chile y los perjuicios consiguientes para estos individuos, que fueron principalmente dos. Una fue la guerra comercial que practicaron los países aliados con la confección de las «listas negras» de las empresas con capital alemán o de las que tenían relaciones comerciales con alemanes o Alemania para asfixiarlas económicamente. Y la otra fue la difusión de un sentimiento simpatizante con los aliados entre la opinión pública latinoamericana en la mayoría de los periódicos de los tres países.

Ante este escenario, la comunidad alemana reaccionó y diseñó una estrategia defensiva: en el plano económico, intentó camuflar sus productos mediante el uso de nombres de socios comerciales y reorientó sus relaciones de comercio hacia el mercado interno de los Estados vecinos y latinoamericanos en general. Además, la guerra económica provocó que varios grupos de interés se fusionaran con el objetivo de convertirse en grupos de presión e influir en la política. Por ejemplo, en 1916 se establecieron cámaras de comercio en Buenos Aires, Valparaíso y Montevideo. Y en Río de Janeiro se fundó la asociación de empresas brasileñas alemanas.

Al principio de la guerra se crearon sociedades benéficas y comités de prensa e información para abordar los problemas más urgentes. El punto culminante fue el establecimiento de la llamada Volksbünde, que aspiraba a unir a todos los alemanes y sus descendientes bajo un ideal nacional, pero las tensiones en su seno fueron constantes. A raíz de la entrada de Estados Unidos en la guerra 
y, sobre todo, tras el hundimiento de barcos latinoamericanos por parte de los submarinos alemanes, la situación se complicó, sobre todo en Argentina y Brasil, con saqueos en instituciones y comercios alemanes (Rinke, 2014: 171-176).

El caso de los alemanes en Brasil fue estudiado por Luebke, quien señala que el sentimiento antialemán existía antes de la PGM en sectores de la prensa y entre los intelectuales brasileños por el temor a que Alemania tuviera un plan diseñado para crear un protectorado en el sur del país aprovechando la presencia de un número importante de inmigrantes germanos. Iniciada la guerra de 1914, la propaganda antialemana se intensificó por parte de la prensa simpatizante de los aliados, que centró sus críticas en el ministro de Relaciones Exteriores de Brasil, Lauro Müller, cuyos padres habían nacido en Alemania. Sin embargo, los problemas para los inmigrantes germanos en Brasil comenzaron en abril de 1917, cuando un submarino alemán hundió el carguero brasileño Paraná frente a la costa francesa. La noticia se conoció el mismo día de la declaración de guerra de Estados Unidos a Alemania (Luebke, 1987: 70-71, 122 y 126).

Los ánimos se caldearon en Brasil. Alemania no satisfizo las reclamaciones del Gobierno brasileño y el 11 de abril se produjo la ruptura de las relaciones diplomáticas y se confiscaron cerca de medio centenar de barcos mercantes alemanes amarrados en puertos brasileños. Además, al día siguiente se produjeron manifestaciones frente a las legaciones alemanas y austriacas, así como ataques a establecimientos comerciales, clubes sociales y sedes de periódicos regentados por la comunidad germana en las principales ciudades: Río de Janeiro, São Paulo y Porto Alegre. En esta última ciudad, los disturbios contra la colonia alemana continuaron tres días más, en los que fueron asaltados y quemados cerca de trescientos edificios. La mayoría de los miembros de la comunidad germana huyeron de la ciudad y encontraron refugio en la sierra (Ibídem: $127,129$ y $135-136)$.

Una segunda ola de disturbios contra los intereses de los germano-brasileños se generaron tras la declaración de guerra de Brasil a Alemania el 26 de octubre de 1917. Esta declaración bélica estuvo acompañada de la prohibición de las publicaciones en alemán y del cierre de las escuelas que no enseñaran en portugués. Por lo que, precisamente, los periódicos y escuelas de origen alemán fueron el blanco de la nueva oleada de violencia en ciudades como Curitiba, Pelotas, Petrópolis y Río de Janeiro (Ibídem: 163-164).

Al hundimiento en octubre del buque brasileño Macao por los submarinos alemanes, se añadieron a principios de noviembre el de otros dos (el Acary y el Guahyba). El Gobierno brasileño promulgó la ley de guerra del 16 de noviembre que permitía anular los contratos de obras públicas que habían sido negociados con las empresas alemanas, prohibir cualquier concesión adicional de nuevas tierras a los súbditos alemanes para su asentamiento, controlar los bancos de propiedad alemana en Brasil y eventualmente anular sus licencias y extender medidas similares a las empresas comerciales de propiedad alemana, prohibir la venta de propiedades alemanas e internar a sujetos alemanes (Ibídem: 173175). 


\section{La movilización militar de los alemanes en Chile en 1914}

En Chile, su gobierno no informó a la prensa de su postura sobre el conflicto armado hasta el 8 de agosto de 1914. En la nota se declaraba neutral y se agregaba que las autoridades chilenas actuarían conforme a las normas de la Convención de la Segunda Conferencia de Paz de La Haya de 1907.7 Sin embargo, a pesar de esta neutralidad, las costas chilenas fueron objeto de operaciones de las flotas beligerantes, que violaron esta neutralidad territorial. El suceso más grave fue la batalla que se dio el 1 de noviembre de 1914 frente al puerto de Coronel. Las armadas británicas y alemanas se enfrentaron con el resultado de dos cruceros británicos hundidos. La réplica se dio el 8 de diciembre frente a las islas Malvinas, cuando las naves británicas destruyeron la escuadra comandada por Spee, a excepción del Dresden, que logró huir al archipiélago de Juan Fernández, aunque luego fue interceptado por fuerzas navales británicas y, finalmente, hundido por los marineros alemanes (Couyoumdjiam, 1977: 192-193).

En tierra, las comunidades de inmigrantes de países implicados empezaron a reaccionar. Así, la colonia francesa en Chile envió, para que se integraran en el ejército francés, a unos 850 reservistas en el buque Orduña, que partió el 19 de agosto del puerto de Valparaíso. Y las autoridades diplomáticas y consulares francesas trataron de controlar a la colonia convocándola a diferentes reuniones y organizando diversos comités de decisión y de planificación de la retaguardia, como la recaudación de fondos y el apoyo a las familias de los reservistas que habían partido al frente europeo (Carrellán y Llosa, 2018).

Los representantes diplomáticos y consulares de Alemania en Chile trataron también de controlar los comportamientos de la colonia en el nuevo contexto bélico. Así, en los primeros días de agosto estos funcionarios, junto con las asociaciones más relevantes de la colectividad, se dedicaron a insertar avisos en la prensa llamando a la movilización militar e invitando a sus nacionales a reuniones en distintos lugares según las ciudades chilenas: en el Club Alemán de Santiago (que se ubicaba en el Portal Mac-Clure, frente a la plaza de Armas) ${ }^{8}$ o en las instalaciones del Club Alemán de Gimnasia de Concepción. ${ }^{9}$

Respecto al reclutamiento, los medios escritos dieron información sobre el proceso y ofrecieron una serie de cifras sobre su resultado: el diario El Sur de Concepción hablaba de 1.000 voluntarios reclutados en esa ciudad ${ }^{10}$ y El Diario Ilustrado mencionaba 200 en Santiago y Valparaíso, 50 en Osorno, 70 en Valdivia y 25 en La Unión. ${ }^{11}$

Se iniciaba de este modo una rivalidad en la prensa chilena entre las distintas colonias extranjeras inmersas en el conflicto por aparentar más fortaleza y

7. El Mercurio, Santiago de Chile, 8 de agosto de 1914, pág. 10.

8. El Sur, Concepción, 3 de agosto de 1914, pág. 7; El Diario Ilustrado, Santiago de Chile, 7 de agosto de 1914, pág. 2.

9. El Sur, Concepción, 6 de agosto de 1914, pág. 1.

10. El Sur, Concepción, 4 de agosto de 1914, pág. 1.

11. El Diario llustrado, Santiago de Chile, 7 de agosto de 1914, pág. 2. 
por enviar el mayor número de combatientes a Europa. Por ejemplo, en el caso de los franceses, el periódico El Sur señalaba el 4 de agosto que ya había 700 dispuestos a incorporarse al ejército francés y se esperaba que se llegase a 3.000 voluntarios en los próximos días. ${ }^{12}$

Un gran número de alemanes residentes en Chile, al igual que los miembros de otras colonias involucradas en la guerra, se comprometieron con la defensa de su país y viajaron al frente de batalla. De este modo, se quebró el esfuerzo que había realizado el Estado chileno de contratar capital humano avanzado en el extranjero. Por tanto, el nuevo escenario bélico desbarataba este empeño y muchos de estos foráneos solicitaron licencias al Gobierno chileno para poder partir a integrarse en sus respectivos ejércitos.

Entre estas personas encontramos al alemán Johannes Brüggen, que llevaba contratado tres años como geólogo en el Ministerio de Industrias y Obras Públicas. ${ }^{13}$ Pero también sabemos de la marcha de los instructores militares contratados por el Ministerio de Guerra, entre ellos, los coroneles Carlos Lothes y Carlos Hanlein y los mayores Ziegler y Hesse. ${ }^{14}$

Por otro lado, entre los germano-chilenos que sirvieron en el ejército alemán encontramos a German Roeschmann, que prestó sus servicios como médico militar y fue condecorado con la Cruz de Hierro por sus actos de valor (así lo confirmó confidencialmente el ministro de Alemania en Chile a las autoridades chilenas). ${ }^{15}$ Hay constancia de que 67 exalumnos del Colegio Alemán de Valparaíso fueron a combatir al frente europeo, algunos de nacionalidad chilena, y de que de ellos fallecieron 18. Asimismo, entre los miembros de la comunidad alemana de la ciudad puerto que se enrolaron en el ejército alemán, hallamos a Phillip Theodor Scdmidt, pastor de la Iglesia Luterana, que regresó a Chile en 1920 (Estrada Turra, 2014: 156-157 y 160).

Aun así, a pesar de todos estos ejemplos de alemanes que marcharon al frente, por lo general los voluntarios y reservistas de esta nacionalidad tuvieron muchos inconvenientes para llegar a Europa.

El principal problema fue la dificultad para fletar un barco con los movilizados germano-chilenos rumbo a Alemania, como sí hizo la Pacific Steam Navigation Company con los que se dirigieron a incorporarse los ejércitos aliados. La compañía británica se negó a vender pasajes a alemanes y austriacos. ${ }^{16}$ Por su parte, la naviera alemana Kosmos dejó de operar y sus buques quedaron amarrados en los puertos chilenos por miedo a ataques de la flota enemiga, ${ }^{17}$ por lo que no pudo replicar a la empresa británica y llevar a los reclutas alemanes a Europa.

12. El Sur, Concepción, 4 de agosto de 1914, pág. 1.

13. El Mercurio, Santiago de Chile, 5 de agosto de 1914, pág. 11.

14. El Diario llustrado, 5 de agosto de 1914, pág. 2.

15. Ministro extraordinario y plenipotenciario de Alemania en Chile a subsecretario del Ministerio de RR. EE. de Chile, doc. núm. 2536, Santiago, 8 de diciembre de 1914, en Archivo General Histórico del Ministerio de RR. EE. de Chile, Santiago de Chile (en adelante, AGHMRE), vol. 1864, Ministerio RREE, Secc. Diplomática.

16. El Mercurio, Santiago de Chile, 12 de septiembre de 1914, pág. 2.

17. El Sur, Concepción, 3 de septiembre de 1914, pág. 4. 
Ante esta coyuntura, el representante de la Legación alemana en Chile solicitó al Ministerio chileno de Relaciones Exteriores que obligara a la mencionada compañía británica de vapores a que aceptara pasajeros alemanes y austriacos en sus naves. Pero el ministro chileno, Manuel Salinas, resolvió el asunto aludiendo que no tenía la facultad legal para forzar una decisión así en tiempos de paz y mucho menos la tenía en ese contexto bélico donde la naviera tenía bandera de uno de los países combatientes. ${ }^{18}$

Otro de los inconvenientes fue el de la imposibilidad de la Legación de Alemania en Chile de extender salvoconductos ni visar pasaportes para las personas que quisieran viajar en buques de bandera de los países aliados desde los puertos americanos. La única excepción que podían hacer los funcionarios alemanes era la de los individuos que viajasen en comisión del Gobierno de Chile..$^{19}$

Por tanto, muchos de los voluntarios de origen alemán que pretendieron llegar a Europa lo hicieron con pasaportes chilenos. Cuando esta situación fue detectada, las autoridades británicas iniciaron una serie de protestas ante el Gobierno de Chile. En un principio, el ministro de Relaciones Exteriores chileno trasladó el problema a su homólogo en el Ministerio del Interior para que los intendentes y gobernadores solo expidieran los pasaportes a ciudadanos chilenos, de manera que los extranjeros tuvieran que solicitarlos a los agentes diplomáticos o consulares de sus respectivos países. ${ }^{20}$

Por su parte, el ministro del Interior respondió que los empleados de su departamento no estaban cometiendo ninguna negligencia por cuanto la legislación chilena otorgaba pasaportes chilenos a los hijos de extranjeros, nacidos en Chile, que presentasen un certificado de no estar inscritos en las legaciones o consulados como súbditos o ciudadanos de los países de sus padres. ${ }^{21}$

El representante chileno en Gran Bretaña, Agustín Edwards, reconocía que no podía negar los pasaportes a quien traía los documentos en regla y confesó al ministro chileno de Relaciones Exteriores que había otorgado pasaportes a cuatro chilenos de origen extranjero; Edwards, ante las dudas que tenía sobre la posible doble nacionalidad, había obligado a firmar a aquellos un documento bajo juramento de que «en ningún caso ejecutarían acto alguno que importara infringir los deberes de neutralidad que incumben a todos los ciudadanos chilenos en el conflicto» que se desarrollaba. Como solución, el diplomático chileno en Londres propuso a su ministro que las autoridades chilenas solo proporcionaran pasaportes a ciudadanos chilenos que estuvieran

18. Ministro de RR. EE. de Chile a ministro plenipotenciario y enviado extraordinario de Alemania en Chile, Confidencial núm. 8, Santiago, 25 de septiembre de 1914, en AGHMRE, vol. 471, M. RREE, Oficios confidenciales a misiones residentes, 1914.

19. Ministro de RR. EE. de Chile a ministro extraordinario y plenipotenciario de Alemania en Chile, Santiago, 28 de septiembre de 1914, en AGHMRE, vol. 1891, M. RREE, Secc. Diplomática.

20. Ministro de RR. EE. de Chile a ministro del Interior de Chile, Confidencial núm. 28, Santiago, 23 de septiembre de 1914, en AGHMRE, vol. 471, M. RREE, Oficios confidenciales a misiones residentes, 1914.

21. Ministro del Interior a ministro de RR. EE. de Chile, Santiago, 13 de noviembre de 1914, en AGHMRE, vol. 509, M. RREE, Oficios confidenciales recibidos de varios ministerios, 1914. 
inscritos en los registros electorales y hubieran realizado el servicio militar obligatorio. ${ }^{22}$

En este sentido, la policía británica se mostró muy celosa de la entrada en su territorio de ciudadanos chilenos de origen alemán y detuvo a varios, como a Enrique Wagemann Gunther, en Plymouth, cuando trataba de viajar al continente europeo para recibir atención médica. En este caso, el representante chileno en Londres realizó gestiones para su liberación. ${ }^{23}$ También fueron arrestados por las autoridades británicas 18 alemanes residentes en Chile, cuando llegaron a Gran Bretaña procedentes de Nueva York en el vapor Oscar II, aunque no portaban en el momento de su detención los pasaportes chilenos. ${ }^{24}$

Asimismo, tenemos constancia de la advertencia del cónsul de Bélgica en Valparaíso a su legación diplomática en Santiago, fechada en noviembre de 1914, de que tenía información fiable de que los alemanes residentes en la ciudad portuaria conseguían pasaportes chilenos en la prefectura de policía previo pago, de que luego los pasaportes eran visados por el intendente de Valparaíso y el Consulado de Italia en ese puerto y de que, seguidamente, estos reservistas alemanes se embarcaban en vapores italianos en Buenos Aires que llegaban a Génova y de ahí continuaban hacia Alemania. El cónsul alentaba al ministro de la Legación belga a que transmitiera esta información a las autoridades británicas para que intentaran arrestarles en Gibraltar. El cónsul cifraba en 50 a los reservistas germanos que habían partido de Valparaíso, pero señalaba que de puertos y ciudades del sur de Chile podrían haber marchado muchos más, al ser numerosa la colonia alemana en esa zona. ${ }^{25}$

Por tanto, observamos que los voluntarios de origen alemán residentes en Chile tuvieron que ingeniárselas para salvar las dificultades de incorporarse al ejército germano desde Chile a través de pasaportes chilenos para burlar los vetos de las navieras de bandera de países aliados, ya que las de capital germano dejaron de navegar una vez comenzada la guerra. Entre las rutas seguidas, destacaba la de Chile a Estados Unidos y desde allí a Alemania. Otra ruta fue la que llevaba a la Europa mediterránea tras embarcar en Buenos Aires en barcos de bandera italiana.

22. Ministro plenipotenciario de Chile en Gran Bretaña a ministro de RR. EE. de Chile, Confidencial núm. 494, Londres, 28 de octubre de 1914, en AGHMRE, vol. 502, Legación de Chile en Gran Bretaña, Oficios confidenciales recibidos, 1914.

23. Ibídem, Confidencial núm. 590, Londres, 7 de diciembre de 1914, en AGHMRE, vol. 502, Legación de Chile en Gran Bretaña, Oficios confidenciales recibidos, 1914.

24. Ibídem, Confidencial núm. 569, Londres, 3 de diciembre de 1914, en AGHMRE, vol. 502, Legación de Chile en Gran Bretaña, Oficios confidenciales recibidos, 1914.

25. Copia de carta confidencial del cónsul belga en Valparaíso al ministro de la Legación de Bélgica en Chile, Valparaíso, 5 de noviembre de 1914, en Centre des Archives Diplomatiques de Nantes, Francia, 616PO/1/123, archivos repatriados de la Legación de Francia en Santiago de Chile. 


\section{La organización de la retaguardia en Chile por la comunidad alemana}

Al igual que la movilización militar, la organización de la retaguardia en Chile estuvo a cargo de los responsables de la legación y de los consulados alemanes. Estos funcionarios, entre otras medidas, se dedicaron a solicitar la aportación de fondos económicos para aliviar la situación de las familias de los soldados que marcharon a Europa, así como para ayudar a las viudas y los huérfanos. Por ejemplo, en la ciudad de Concepción se constituyeron dos comités de ayuda, uno compuesto por hombres y otro, por mujeres, y ambos controlados por el consulado, ya que los comités tenían al cónsul y a su esposa como presidentes. ${ }^{26}$ Y como muestra de la reafirmación nacional, los donantes más importantes y sus empresas aparecían en la prensa diariamente en reiterados avisos. En el caso de Concepción, los principales donantes fueron Ernst Gesswein, cónsul alemán en la ciudad; Arturo Junge (de la empresa Timmermann y Cía.); Adolfo Eskuche (de una fábrica de vela); Heinrich Müeller (Casa Caratens y Cía.); Eduardo Caratens (dirección: Barros Arana, 237); Carlos Messing (dirección: Barros Arana, 817); Jerman Vogel (Oscar Spoerer y Cía.), y A. Wieberg (R. Schuz y Cía.). ${ }^{27}$

Otra forma de colaborar activamente por parte de algunos miembros de la colonia alemana, pero de manera clandestina, fue la transmisión de información a través de instalaciones telegráficas inalámbricas a los barcos germanos que navegaban por el Pacífico. Las denuncias de los diplomáticos de las potencias aliadas fueron constantes y la policía chilena actuó con contundencia para desmantelar estas infraestructuras y atajar toda duda acerca de la neutralidad de las autoridades chilenas durante la guerra. ${ }^{28}$

La colonia alemana, además, se enfrentó a otros problemas, como el «apagón informativo» de las noticias recibidas desde Alemania. Las noticias recibidas en Chile eran transmitidas por cables y dependían de agencias cuyos propietarios eran británicos y franceses, de manera que no había comunicaciones directas con Alemania. La prensa se hizo eco de esta circunstancia en innumerables ocasiones. En este sentido, se manifestaban los directores del Club Alemán de Santiago, ${ }^{29}$ por ejemplo.

Precisamente, esta última institución, junto con la Legación alemana en Santiago, se preocupó por difundir en los medios noticias llegadas directamente desde Alemania sobre el desarrollo de la guerra. Una muestra de lo que decimos la encontramos el 6 de septiembre en el diario El Mercurio de Santiago, donde se detallan los avances del ejército alemán en Francia y Bélgica. ${ }^{30}$

26. El Sur, Concepción, 12 de agosto de 1914, pág. 1.

27. El Sur, Concepción, 7, 8 y 9 de agosto de 1914, pág. 1.

28. Ministro de RR. EE. de Chile a ministro plenipotenciario y extraordinario de Francia en Chile, Confidencial núm. 13, Santiago, 4 de noviembre de 1914, en AGHMRE, vol. 471, M. RREE, Oficios confidenciales a misiones residentes, 1914.

29. El Diario llustrado, Santiago de Chile, 3 y 7 de agosto de 1914, pág. 2.

30. El Mercurio, Santiago de Chile, 6 de septiembre de 1914, pág. 15. 
En relación con este asunto, existió una "guerra mediática» de la información desatada tras el inicio de la contienda. Tras el estallido del conflicto, las noticias relativas a la guerra eran las difundidas por la agencia francesa Havas y los cables telegráficos británicos que dominaban el sistema informativo en América Latina por entonces; la comunidad alemana intentó contrarrestar este sistema sin éxito. Al inicio de la guerra, los británicos sabotearon los cables submarinos alemanes del mar del Norte, por lo que se imposibilitó la transmisión de noticias desde Alemania hacia el continente americano. Así, la conexión telegráfica más importante para Chile durante los años previos y durante la PGM fue la llamada línea Galveston. Esta conexión nacía en Londres y llegaba a Nueva York, y de esta ciudad iba, por vía terrestre, hasta Galveston (Texas) y, de aquí, a Veracruz (México), y pasaba luego por las repúblicas centroamericanas hasta Colón (Panamá). Después, conectaba a las ciudades del Pacífico (Callao, Iquique, Valparaíso) y llegaba a Buenos Aires. Así pues, en 1914 nos encontramos con un panorama comunicacional para Chile en el que los cables telegráficos fueron predominantemente de compañías británicas y la agencia de noticias que suministraba las mismas, la Havas, era francesa (Carrellán, 2017).

Para contrarrestar esta situación, la colonia alemana intentaba informarse a través de los diarios de la colectividad, como el Deutsche Zeitung für Chile, ${ }^{31}$ de Valparaíso. Siendo consciente de la coyuntura, el periódico El Sur, de Concepción, publicaba las noticias de dicho rotativo e incluso transcribía editoriales del mismo en los que los redactores alemanes se quejaban de la falta de noticias recibidas directamente de Alemania; en uno de ellos calificaban de calumniosas y difamatorias las noticias que transmitían las agencias cablegráficas, que eran principalmente británicas y francesas. El mismo editorialista alemán decía que la prensa chilena no debía transmitir esas noticias tendenciosas porque tergiversaban la verdad. En esta línea, el diario El Sur indicaba que tratarían de ser lo más imparciales posible en sus informaciones sobre la guerra europea. ${ }^{32} \mathrm{El}$ periódico regional señalaba que el problema venía por el monopolio de las líneas cablegráficas interoceánicas de Francia y Gran Bretaña. ${ }^{33}$

Rinke (2014: 172) señala que las asociaciones de empresas, casas comerciales y bancos regentados por alemanes en Latinoamérica apoyaron los esfuerzos de propaganda alemana a través de donaciones a varios periódicos latinoamericanos y contribuyeron con su participación a la fundación de un periódico en español en Buenos Aires: La Unión.

Esta misma reacción fue la que tuvo la colonia alemana en Perú, con la creación de dos publicaciones (La Guerra Gráfica, fundada en Lima en 1914, y Germania, publicada en lquitos a partir de 1916) para difundir un discurso sobre la guerra que fuera diferente al del resto de los diarios y para defender los intereses económicos y políticos de la comunidad alemana en el país andino (Martin, 2015: 265).

31. Witker (2000: 55-56) señala que este diario fue el decano de la prensa en alemán en Chile, el cual se había fundado en 1870 con otro nombre y había adoptado esa denominación en 1909.

32. El Sur, Concepción, 12 de agosto de 1914, pág. 1.

33. El Sur, Concepción, 3 de septiembre de 1914, pág. 1. 
Por otro lado, y de nuevo en Chile, las autoridades alemanas sufrieron la violación del secreto de su correspondencia. El 18 de agosto de 1914, el representante de la Legación germana, Erckert, denunció ante el Ministerio chileno de Relaciones Exteriores esta situación y acusó al servicio telegráfico de la compañía West Coast of America Telegraf. Erckert exigía un proceso criminal que investigara las posibles responsabilidades, pero el subsecretario del Ministerio chileno zanjó la cuestión y no estimó oportuno llevar a cabo ninguna investigación, ya que creía que todo se debió a la negligencia de un empleado de la empresa que había sido despedido tras la queja del Ministerio de Relaciones Exteriores al gerente de la compañía. ${ }^{34}$

Un nuevo incidente se dio en octubre, cuando el jefe de la Legación alemana en Chile puso en conocimiento de las autoridades chilenas que había desaparecido la correspondencia que traía para ellos un vapor inglés desde Montevideo. Por ello, el representante de la diplomacia alemana solicitó al Gobierno de Chile que en lo sucesivo ningún barco de bandera británica se encargara de transportar su correo. Por su parte, el ministro chileno de Relaciones Exteriores contestó que no tenía noticias de ese suceso y que lo pondría en conocimiento del Ministerio del Interior. ${ }^{35}$

Sin embargo, las complicaciones para la colonia alemana no terminaron aquí, y sus miembros pronto padecieron las limitaciones a las transacciones económicas impuestas por el Gobierno británico a las empresas y bancos alemanes radicados en cualquier parte del mundo, y que afectaron al desarrollo de las compañías regentadas por germano-chilenos en Chile. Así se desprende de la documentación que hemos consultado de la correspondencia del ministro de Relaciones Exteriores chileno con distintos cargos de su Gobierno y agentes diplomáticos chilenos y extranjeros.

Sobre este asunto existió una protesta del representante de la diplomacia alemana en Chile porque la prensa chilena recogía informaciones donde mencionaba la difícil situación de la banca alemana en Chile citando como fuente a Agustín Edwards, ministro de Chile en Londres. El jefe de la Legación de Alemania solicitaba al Gobierno de Chile que sus funcionarios se mantuvieran al margen de lo que calificaba de artimañas comunicacionales británicas para desacreditar a las entidades alemanas. ${ }^{36}$

Y no solo la banca: muchas empresas de capital alemán en Chile sufrieron los efectos de la guerra. En ese cometido trabajó activamente la Cámara de Comercio Británica en Chile, que logró aglutinar a sus homólogos de las colonias francesas e italianas con apoyo del cuerpo diplomático de Estados Unidos. Su

34. Ministro de RREE de Chile a ministro plenipotenciario de la Legación Alemania en Chile, Confidencial núm. 1, Santiago, 20 de agosto de 1914, en AGHMRE, vol. 471, M. de RR EE, Oficios confidenciales dirigidos a misiones residentes, 1914.

35. Ibídem, Confidencial núm. 24, Santiago, 31 de octubre de 1914, en AGHMRE, vol. 471, M. de RR EE, Oficios confidenciales dirigidos a misiones residentes, 1914.

36. Ministro plenipotenciario y enviado extraordinario de Alemania en Chile a ministro de RR. EE. de Chile, Memorándum, Santiago, 14 de marzo de 1916, en AGHMRE, vol. 471A, M. RREE, Oficios confidenciales recibidos de misiones residentes, 1914-1925. 
fruto fue el Comité Comercial de los Aliados. Esta organización se esmeró en elaborar una lista de empresas que tenían capital o empleados alemanes, o incluso vínculos comerciales con Alemania. Su labor fue muy eficaz y pronto los negocios señalados sufrieron sus consecuencias negativas (Couyoumdjiam, 1986: 146).

Como ejemplo, conocemos las dificultades por las que pasó la Empresa de Tranvías Eléctricos de Valparaíso (ETEV), fundada en Berlín en 1903 por AEG y el Deutsche Bank después de conseguir la concesión municipal. La PGM supuso que la ETEV no tuviera acceso a los repuestos ni a nuevos vagones, y lo que fue más grave es que por presiones externas se les cortó el suministro de carbón chileno, esencial para la producción de la electricidad (Castillo y Vila, 2017: 60-62).

Las presiones vendrían de los aliados y sus «listas negras» de empresas con vinculación germana. Esta situación generó que la ETEV acometiera continuadas subidas de las tarifas de sus servicios, con lo que provocó que surgieran revueltas populares como la que ocurrió el 1 de diciembre de 1914, el día en que, después de una manifestación, se atacaron las oficinas del tranvía, los bancos germanos y el consulado alemán. ${ }^{37}$ Por tanto, lo que en origen había sido un problema de subida de las tarifas de una compañía se convirtió en una revuelta antigermánica.

Por otra parte, los representantes diplomáticos alemanes también sufrieron las consecuencias de la guerra. En este caso, Friedrich Karl von Erckert, ministro plenipotenciario y enviado extraordinario de Alemania en Chile, recibió amenazas anónimas de muerte y lo puso en conocimiento de las autoridades chilenas el 4 de septiembre. El ministro de Relaciones Exteriores chileno trasladó esta denuncia al Ministerio del Interior para que se tomaran las medidas oportunas y se protegiera la Legación germana día y noche. ${ }^{38}$

En este contexto, se crearon varias instituciones que velaron por la defensa de los intereses de la colectividad alemana en Chile como la Liga Chileno-Alemana y la Cámara de Comercio Alemana en 1916, así como el Cementerio Alemán de Valparaíso al año siguiente y el Club de los Maxistas (1919) para auxiliar a los huérfanos de los combatientes en Europa (Estrada Turra, 2014: 146).

\section{Conclusiones}

Este trabajo es una primera exploración sobre la movilización de los alemanes residentes en Chile y la organización de la retaguardia en territorio chileno, así como de los comportamientos y los problemas a los que se enfrentaron en el

37. Ministro plenipotenciario de Chile en Gran Bretaña al ministro de RR. EE. de Chile, Confidencial núm. 604, Londres, 8 de diciembre de 1914, en AGHMRE, vol. 502, Legación de Chile en Gran Bretaña, Oficios confidenciales recibidos, 1914.

38. Ministro de RR. EE. de Chile al ministro plenipotenciario y extraordinario de Alemania en Chile, Confidencial núm. 5, Santiago, 14 de septiembre de 1914, en AGHMRE, vol. 471, M. RREE, Oficios confidenciales a misiones residentes, 1914. 
contexto de la PGM. En este sentido, por la información recopilada observamos que los representantes diplomáticos y consulares alemanes trataron de controlar las actuaciones de la colectividad. En primer lugar, organizando la movilización militar, que sería importante si damos por buena las cifras publicadas en los diarios consultados; un número de voluntarios y reservistas que no hemos determinado pero que tuvo que ser cuantioso. Sin embargo, los alemanes tuvieron dos problemas que no padecieron los movilizados franceses: la imposibilidad de viajar con pasaportes alemanes y la inexistencia de un buque organizado por las autoridades alemanas en Chile que los llevara a Alemania.

El censo de 1920 muestra que, por vez primera, el número de alemanes retrocede si observamos los censos chilenos levantados entre 1854 y 1940; efectivamente fue el censo de 1920 el que reflejó una reducción de 1.700 personas respecto al censo levantado en 1907. Este hecho nos hace pensar que la PGM impactó en la composición numérica de la colonia alemana en Chile. Entre las posibles respuestas para explicar este descenso estaría la marcha de reservistas a luchar al frente europeo, pero también podría estar la nacionalización chilena de un número destacado de alemanes para escapar del control de las autoridades de su país o para no sufrir algún tipo de discriminación por su condición de alemán en su vida cotidiana.

El segundo foco de atención de los funcionarios diplomáticos alemanes fue la articulación de la retaguardia en Chile mediante comités que tomaban las decisiones en ese contexto de guerra. Entre estas decisiones estaría la recaudación de fondos para ayudar a las familias de los movilizados en el frente.

El contexto de los germanos en Chile parece muy adverso durante la guerra: las amenazas de muerte que sufrió el representante del Gobierno alemán en Chile, Friedrich Karl von Erckert; los ataques sufridos por las empresas e instituciones alemanas; las dificultades económicas que padecieron las compañías y bancos germanos a través de las «listas negras»; y el «apagón informativo» directo con Alemania tras el sabotaje del ejército británico a los cables submarinos alemanes y el control de la información que ejercieron las agencias de noticias aliadas.

Sin embargo, a pesar de las dificultades que pudieran padecer, pensamos que, entre los inmigrantes europeos en general, y alemanes en particular, prevaleció la costumbre de mostrar su identidad de origen, ya que un número importante de ellos acudieron a la llamada de la patria a defenderla por medio de las armas. Seguramente existían mecanismos legales e ilegales para no ir a luchar al hemisferio norte, pero muchos mostraron su fidelidad aun a riesgo de perder la vida. En muchos casos, como hemos visto, se trataba de profesionales con una vida acomodada con vínculos laborales en agencias estatales, universidades y empresas relevantes.

Entre las justificaciones estaría el nacionalismo exacerbado de principios del siglo XX, pero también contribuyó la actitud del Estado chileno con la política de atracción de estos inmigrantes, que permite entender que se promoviera el orgullo de pertenencia a la colectividad europea, y a la alemana, en nuestro caso. Las autoridades chilenas consideraron a estas personas como superiores, en moralidad y en civilización, al resto de la población chilena, y les concedieron 
unos beneficios de los que se privó a los demás habitantes del país. Esta situación explicaría uno de los motivos más relevantes, a nuestro juicio, por el interés para identificarse con un origen europeo, puesto que esta condición les favorecía en su vida cotidiana en la sociedad chilena.

Esperamos contribuir en el futuro con los resultados de la investigación en torno a la movilización global de las comunidades de origen francés, británico y alemán residentes en Chile que nos ayuden a entender la visión de conjunto de las reacciones de estos colectivos, para la cual usaremos una versión reducida de los datos de este trabajo.

\section{Bibliografía}

AlARCÓN, Cristina (2009). «Construcción del Estado nacional chileno a través de sociedades de referencia: la recepción de modelos de formación docente y militar alemanes desde 1880-1920 en Chile». En: HeRnÁNDEZ DíAz, José María (coord.). Influencias alemanas en la educación española e iberoamericana. Salamanca: Globalia, págs. 367379.

Alfonso, José A. (1900). Un viaje a Valdivia. La civilización alemana en Chile. Santiago: Imprenta Moderna.

ALMONACID, Fabián (2004). «Españoles en Chile: reacciones de la colectividad frente a la República, Guerra Civil y Franquismo (1931-1940)". Revista Complutense de Historia de América, Madrid, 30, págs. 149-185.

AnWANDTER, Carl (2001). Desde Hamburgo a Corral. Diario de viaje a bordo del velero Hermann. Valdivia / Santiago de Chile: Universidad Austral de Chile / Pehuén, págs. 13-28.

ARANDA, Diego; LlarenA, José María y TenAJo, Rafael (1920). La colonia alemana en Chile. Santiago: Imprenta Claret.

BARRIOS, Mario (1970). Historia diplomática de Chile. Barcelona: Ariel.

Bernedo, Patricio (1999). «Los industriales alemanes de Valdivia, 1850-1914». Historia, Santiago de Chile, 32, págs. 5-42.

BLANCPAIN, Jean Pierre (1987). Los alemanes en Chile (1816-1945). Santiago de Chile: Hachette.

BRAHM, Enrique (2014). «La consolidación de una colonia en la Patagonia Occidental: chilenos y alemanes en torno a la creación de la Provincia de Llanquihue (capital Puerto Montt, Chile)». Magallania, Punta Arenas, 42 (1), págs. 77-92.

Bravo Valdivieso, Germán (2005). La Primera Guerra Mundial en la costa de Chile: una neutralidad que no fue tal. Santiago: Ediciones Altazor.

CARREllán Ruiz, Juan Luis (2017). "Las imágenes del comienzo de la Primera Guerra Mundial en "El Mercurio" de Santiago de Chile: De la "tragedia de Sarajevo" al inicio del "conflicto europeo"». CUHSO Cultura Hombre Sociedad, Temuco, 27 (2), págs. 153-173.

CARRELlán Ruiz, Juan Luis y Llosa, Alvar de la (2018). «L'appel de la patrie: les réservistes et les volontaires français du Chili pendant la Première Guerre mondiale». Guerres mondiales et conflits contemporains, París, 270, págs. 7-23.

CARRELlán, Juan Luis y SÁEZ, Andrés (eds.) (2014). La Primera Guerra Mundial: a cien años de la guerra que acabaría con todas. Temuco: Universidad de La Frontera. 
CAStillo, Simón y ViLA, Waldo (2017). «Los tranvías de Valparaíso. El primer sistema de transporte público del puerto (1863-1953)». Revista 180, 40, págs. 54-67.

CID, Gabriel y SAN Francisco, Alejandro (2009). Nación y nacionalismo en Chile: siglos XIX y Xx. Santiago de Chile: Centro de Estudios Bicentenario.

Compagnon, Olivier (2007). “Si loin, si proche...”. La Première Guerre mondiale dans la presse argentine et brésilienne». En: LAMARRE, Jean y DELEUZE, Magali (eds.). L'envers de la médaille. Guerres, témoignages et représentations. Québec: Presses Universitaires de Laval, págs. 77-91.

Compagnon, Olivier (2009). «Entrer en guerre? Neutralité et engagement de l'Amérique latine entre 1914 et 1918». Relations Internationales, París / Ginebra, 137, págs. 31-43.

Compagnon, Olivier (2013). L'adieu à l'Europe. L'Amérique Latine et la Grande Guerre. París: Fayard.

Compagnon, Olivier, et al. (eds.) (2018). La Gran Guerra en América Latina: una historia conectada. Ciudad de México: CEMCA.

CouYOUMDJIAN, Juan Ricardo (1974-1975). «El mercado del salitre durante la Primera Guerra Mundial y la postguerra, 1914-1921. Notas para su estudio». Historia, Santiago de Chile, 12, págs. 13-55.

CoUYOUMDJIAN, Juan Ricardo (1977). «En torno a la neutralidad chilena durante la Primera Guerra Mundial». En: SÁnCHEZ, Walter y PereIRA, Teresa. Ciento cincuenta años de política exterior chilena. Santiago de Chile: Universidad de Chile, págs. 180-205.

CouYoumdJIAN, Juan Ricardo (1986). Chile y Gran Bretaña durante la Primera Guerra Mundial y la posguerra, 1914-1921. Santiago de Chile: Andrés Bello / PUC.

CouyoumdJIAN, Juan Ricardo y MuÑOz, María Angélica (2002). "Chilenos en Europa durante la Primera Guerra Mundial». Historia, Santiago de Chile, 35, págs. 35-62.

CuENCA, Álvaro (2006). La colonia británica de Montevideo y la Gran Guerra. Montevideo: Torre del Vigía Editores.

DUFNER, Georg; FERMANDOIS, Joaquín y RINKE, Stefan (eds.) (2016). Deutschland und Chile, 1850 bis zur Gegenwart. Ein Handbuch / Alemania y Chile, de 1850 hasta hoy. Un manual. Stuttgart: Hans-Dieter Heinz.

EstradA TURRA, Baldomero (2005). «La colectividad alemana de Valparaíso durante la primera mitad del siglo XX». Revista de Historia, Concepción, 15 (1), págs. 113-124.

Estrada TURRA, Baldomero (2009). «República y exilio español en el fin del mundo: Valparaíso, Chile». Revista de Indias, Madrid, 69 (245), págs. 95-122.

EstradA TURRA, Baldomero (2011). «Integración socioeconómica de la colectividad alemana en Valparaíso (1850-1930)». Historia 396, Valparaíso, 1 (2), págs. 199-235.

EstradA TURRA, Baldomero (2013). «Importancia económica de los alemanes en Valparaíso 1850-1915». América Latina en la Historia Económica, Ciudad de México, año 20, 2, págs. 151-176.

ESTRADA TURRA, Baldomero (2014). «Instituciones étnicas alemanas en Valparaíso 1850 1930: una forma de defensa de la identidad cultural». Revista de Historia Social y de las Mentalidades, Santiago de Chile, año 18, 1, págs. 139-179.

EstRADA TURRA, Baldomero (2018). La azarosa y difícil aventura de migrar: españoles en Chile (1880-1950). Santiago de Chile: RIL editores.

FERnÁNDEZ Domingo, Enrique (2016). «La Première Guerre mondiale et le Chili; de la propagande et la maîtrise de l'information à la redéfinition de l'identité nationale». Guerres Mondiales et Conflicts Contemporains: Revue d'Histoire, París, 264, págs. 91-110. 
FERNÁNDEZ Domingo, Enrique (2018). «L'Amérique Latine et ees deux Guerres mondiales». Guerres Mondials et Conflicts Contemporains: Revue d'Histoire, París, 270.

GóngORA, Mario (1998). Ensayo histórico sobre el concepto de Estado en Chile siglos XIX y xx. Santiago de Chile: Editorial Universitaria.

Gordon, Milton (1978). Human nature, class and ethnicity. Nueva York: Oxford University Press.

GÜENAGA DE SILVA, Rosario (1989). «La presencia alemana en el extremo austral de América». Jahrbuch für Geschichte Lateinamerikas = Anuario de Historia de América Latina, Münster, 26, págs. 201-227.

HARRIS BuCHER, Gilberto (2012). Emigrantes e Inmigrantes en Chile, 1810-1915. Todo revisitado todo recargado. Valparaíso: Universidad de Playa Ancha.

Hobsbawm, Eric (2000). Historia del siglo xx: 1914-1991. Barcelona: Crítica.

KELLENBENZ, Hermann y SCHNEIDER, Jürgen (1976). «La emigración alemana a América Latina desde 1821 hasta 1930". Jahrbuch für Geschichte Lateinamerikas = Anuario de Historia de América Latina, Münster, 13, págs. 386-403.

KREBS, Andrea; TAPIA, Úrsula y SCHMID, Peter (2001). Los alemanes y la comunidad chileno-alemana en la historia de Chile. Santiago de Chile: Liga Chileno - Alemana.

LÁZARO MONTES, Julián Andrés (2020). «Los alemanes en el Caribe colombiano. Migración, sociabilidad y nacionalsocialismo en Barranquilla, 1919-1945». Historia Contemporánea, 62, págs. 49-77.

LegarRaga, Patricio (2006). Los vascos de Francia en Chile. Tomo I. Santiago: Ka2.

LUEBKE, Frederick C. (1987). Germans in Brazil. A comparative history of cultural Conflict during World War I. Baton Rouge / Londres: Louisiana State University Press.

Maier, Ernesto (prol.) (1910). Los alemanes en Chile. Homenaje de la Sociedad Científica Alemana de Santiago a la Nación Chilena en el centenario de su Independencia. Tomo I. Santiago de Chile: Imprenta Universitaria.

MartiN, Guillemette (2015). «Vivir el conflicto lejos de los campos de batalla. La comunidad alemana del Perú y la Primera Guerra Mundial». Bulletin de l'Institut Français d'Études Andines, 44 (2), págs. 259-281.

MENESES, Emilio (1989). El factor naval en las relaciones entre Chile y los Estados Unidos (1881-1951). Santiago: Ediciones Pedagógicas Chilenas.

NovaK, Fabián y ORTIZ, Jorge (2014). El Perú y la Primera Guerra Mundial. Lima: Fondo Editorial PUCP.

OTERO, Hernán (2009). La guerra en la sangre: los franco-argentinos ante la Primera Guerra Mundial. Buenos Aires: Sudamericana.

PAlAmARA, Graziano (2015). «Entre guerra y paz. América Latina frente a la tragedia del primer conflicto mundial». Anuario Colombiano de Historia Social y de la Cultura, Bogotá, 42 (2), págs. 103-126.

Pellegrini, Amadeo y Aprile, Jorge Ciru (eds.) (1924). El progreso alemán en América. Tomo ı. Santiago de Chile: Editorial Río de la Plata.

PÉREZ, Roberto (2010). «Voluntarios anglo-chilenos en la Primera Guerra Mundial: los gringos de Valparaíso en el ejército de Kitchener». En: Praln, Michelle. Legado británico en Valparaíso. Santiago de Chile: RIL Editores, págs. 122-141.

PHILIPPI, Rodulfo Amando (1946). «Los orígenes de la colonización alemana en Chile». $B A C h H$, Boletín de la Academia Chilena de la Historia, Santiago de Chile, 35, $2 .^{\circ}$ semestre. 
PotTHAST, Bárbara (1999). «A emigración alemana a América Latina». Estudios migratorios, Santiago de Compostela, 7, págs. 107-119.

Ramírez BAccA, Renzo (2015). «Estudios sobre la Primera Guerra Mundial en América Latina. Una mirada comparada». Anuario Colombiano de Historia Social y de la Cultura, Bogotá, 42 (2), págs. 43-73.

RIQUeLME OYARZÚN, Benjamín (2002). «La neutralidad de Chile durante la Primera Guerra Mundial». Revismar, Santiago de Chile, 3, págs. 35-62.

RINKE, Stefan (2014a), «América Latina y la Primera Guerra Mundial, nuevos estudios, nuevas interpretaciones». Iberoamericana. América Latina, España, Portugal, Berlín, 53.

RINKE, Stefan (2014b). «The reconstruction of national identity: German minorities in Latin America during the First World War». En: GoEbeL, Michael y Foote, Nicola (eds.). Immigration and national identities in Latin America. Gainesville: The University Press of Florida, págs. 160-181.

RINKE, Stefan (2017). Latin America and the First World War. Cambridge: Cambridge University Press.

SALINAS MEZA, René (1992). «Los alemanes en Valparaíso, 1860-1960: una comunidad inmigrante (estudio demográfico)». Jahrbuch für Geschichte Lateinamerikas = Anuario de Historia de América Latina. Münster, 29, págs. 309-342.

Samaniego, Mercedes y MedinA, Andrés (coords.) (2016). La Gran Guerra (1914-1918): visiones de Europa y América. Concepción: UCSC.

SanHuEZA, Carlos (2006). Chilenos en Alemania y alemanes en Chile. Viaje y nación en el siglo XIX. Santiago de Chile: Centro de Investigaciones Diego Barros Arana / LOM Ediciones.

Schulze SchneIder, Ingrid (1995). Alemania y América. La llamada del Nuevo Mundo: 500 años de presencia alemana en América. Madrid: Editorial MAPFRE.

Sото, Salvador (1917). Los alemanes en Chile, 1541-1917. Progresos y servicios que les debe la República. Valparaíso: Imprenta Victoria.

Stuven, Ana María y PamplonA, Marco A. (2009). Estado y nación en Chile y Brasil en el siglo XIX. Santiago de Chile: Universidad Católica de Chile.

Tarruella, Ramón (2014). 1914: Argentina y la Primera Guerra Mundial. Buenos Aires: Aguilar.

TATO, María Inés (2011). «El llamado de la patria. Británicos e italianos residentes en la Argentina frente a la Primera Guerra Mundial». Estudios Migratorios Latinoamericanos, Buenos Aires, Centro de Estudios Migratorios Latinoamericanos (CEMLA), 71, págs. 273-292.

TATO, María Inés (2014a). «La Gran Guerra en la historiografía argentina. Balance y perspectivas de investigación". Iberoamericana. América Latina - España - Portugal, Berlín, XIV, 53, págs. 91-101.

TATO, María Inés (2014b). «Italianità d'oltremare. La comunità italiana di Buenos Aires e la guerra». En: Scartabellatı, Andrea; ERMACORA, Matteo y RatTI, Felicita (eds.). Fronti interni. Esperienze di guerra lontano dalla guerra. Nápoles: Edizione Scientifiche Italiane, págs. 213-226.

VERA DE FLACHS, María Cristina (1994). «Emigraciones transoceánicas. Los alemanes en América, 1850-1914. El caso argentino». Cuadernos de Historia Contemporánea, Madrid, 16, págs. 65-98. 
WALDMANN, Peter (1988). «La evolución de las colonias de inmigrantes alemanes en el sur de Chile: conflicto cultural y adaptación paulatina». Jahrbuch für Geschichte Lateinamerikas = Anuario de Historia de América Latina, Münster, 25, págs. 437-453.

WINKLER, Lisette (2010). «Impactos económicos y sociales de la inmigración alemana en Valdivia (Chile) en el siglo XIX». Nuevo Mundo, Mundos Nuevos, París, 10. URL: http:// journals.openedition.org/nuevomundo/57959.

WITKER, Iván (2000). «Aspectos culturales de la inmigración alemana a Chile». Ibero-Americana Pragensia, Praga, XXXIV, págs. 55-56.

YounG, George (1974). Germans in Chile: immigration and colonization, 1849-1914. Staten Island: Center for Migration Studies.

Fecha de recepción: 8 de febrero de 2021

Fecha de aceptación: 15 de abril de 2021

Fecha de publicación: 22 de diciembre de 2021 